\title{
Changes in Employment Prospects for Black Males
}

Two general assessments of black economic progress prevail in the United States today. Prominent economic studies emphasize a converging trend in the earnings of blacks and of whites. Among these studies, Richard Freeman's description of a "virtual collapse in traditional discriminatory patterns in the labor market" makes the point most sharply. James Smith and Finis Welch, although more cautious, reach a similar conclusion. ${ }^{1}$

The assessment of more popular writers is, paradoxically, more complex. It holds that there is a growing split within the black community, with some blacks making significant gains while other blacks are becoming progressively worse off. Some writers view the split in terms of labor supply. They interpret the data as reflecting a growing black middle class

The research for this paper was supported by the U.S. Department of Labor and the Ford Foundation. The paper has benefited from conversations with Robert I. Lerman, David H. Swinton, Douglas A. Wolf, and members of the Brookings panel. Edward Fu of the Department of Labor provided data for the tabulations, and Robert Avery's CRAWTRAN II program was used for the statistical work. I thank Daniel J. Feaster and William G. Coyle for research assistance and Mary G. Mingo for help in preparing the manuscript.

1. Richard B. Freeman, "Changes in the Labor Market for Black Americans, 1948-1972," BPEA 1:1973, p. 67; and James P. Smith and Finis Welch, "Race Differences in Earnings: A Survey and New Evidence," in Peter Mieszkowski and Mahlon Straszheim, eds., Current Issues in Urban Economics (Johns Hopkins University Press, 1979), pp. 40-73. Two economic studies that express more cautious views are James P. Smith and Finis Welch, "Inequality: Race Differences in the Distributions of Earnings," International Economic Review, vol. 20 (June 1979), pp. 515-26; and Richard Butler and James J. Heckman, "The Government's Impact on the Labor Market Status on Black Americans: A Critical Review," in Leonard J. Hausman and others, eds., Equal Rights and Industrial Relations (Industrial Relations Research Association, 1977), pp. 235-81. 
and a growing black "underclass." Other writers view the split in the context of labor demand. For them, the data indicate job rationing and job crowding, processes of discrimination by which very similar individuals can be randomly sorted into very different careers. ${ }^{2}$

Whereas economists have measured progress through individual earnings, more popular assessments have focused on family income. Nonetheless, the two assessments have sufficiently different conclusions to require a serious attempt at reconciliation. The purpose of this paper is to present such a reconciliation for data on black males. Although there are many ways to measure economic progress, the principal focus here is on black males and their prospects for employment.

The popular assessment of black economic progress emphasizes the increasing variance of black experience. By contrast, standard economic models focus not on variance but on central tendencies: median earnings, the "typical" individual described in regression studies, and so on. ${ }^{3}$

In the case of labor market studies, reliance on a single summary statistic has been reinforced by the extensive use of labor market turnover models. In particular, a number of authors have noted the declining participation rate of black males. But labor force participation rates are

2. For a lucid discussion of these two points of view, see "The Black Plight: Race or Class? A Debate between Kenneth B. Clark and Carl Gershman," in the New York Times Magazine (October 5, 1980). Other articles on the split in the black population include John Herbers and others, "Two Societies: America Since the Kerner Report," a four-part series in the New York Times, February 26-March 1, 1978; and Daniel Patrick Moynihan, "The Schism in Black America," The Public Interest, no. 27 (Spring 1972), pp. 3-24; Steven P. Erie, "Public Policy and Black Economic Polarization," Policy Analysis, vol. 6 (Summer 1980), pp. 303-17. A third view that discounts the growth of the black middle class altogether is presented in Robert B. Hill, The Illusion of Black Progress (Washington, D.C.: National Urban League, Research Department, 1978).

3. An early example of a paper that took a more complete approach is Anthony H. Pascal and Leonard A. Rapping: "The Economics of Discrimination in Organized Baseball," in Anthony H. Pascal, ed., Racial Discrimination in Economic Life (Lexington Books, 1972), pp. 119-56. The authors conclude that major league baseball clubs in the late 1960s gave all players equal pay for equal ability (as measured by batting averages, the number of home runs, and so on). But when clubs decided who should be brought from the minor leagues, the clubs maintained much higher standards for blacks than for whites. This led to the paradoxical result that major league black players had higher earnings, on average, than major league white players even though discrimination existed. The paper represents an early attempt to grapple with the problem of censored samples. 
measured on a monthly basis. Typical Markov chain models of turnover predict that most men who are out of the labor force in a given month should work at least some time during the year. If this prediction were correct, a summary statistic like median earnings would capture the experience of most black males.

In the past few years, however, the focus on central tendencies has begun to broaden. The extensive development of the censored sample and qualitative choice estimators has led to the investigation of distributions of outcomes and not simply mean responses. ${ }^{4}$ Moreover, recent work on labor force dynamics by George Akerlof and Brian Main and by others suggests that individuals have far more consistent experiences in the labor market over time than standard Markovian models predict. ${ }^{5}$ This, in turn, indicates that the distribution of individual labor market experiences may be more heterogeneous than previously thought, a conclusion that also points to the need to analyze a full range of outcomes.

\section{Reexamining the Data}

The statistic that forms the basis for many economic analyses of black economic progress is median wage and salary income, an annual series published by the U.S. Bureau of the Census. The statistic includes more than prospects for employment, but is so widely used that it provides an appropriate place to begin the discussion. The statistic is tabulated from

4. Good summaries of the censored sample literature are in Zvi Griliches, Bronwyn H. Hall, and Jerry A. Hausman, "Missing Data and Self-Selection in Large Panels," Annales de l'inséé, nos. 30-31 (April-September 1978), pp. 137-76; and James J. Heckman, "The Common Structure of Statistical Models of Truncation, Sample Selection and Limited Dependent Variables and a Simple Estimator for Such Models," Annals of Economics and Social Measurement, vol. 5 (Fall 1976), pp. 475-92. In the case of models of qualitative choice, the actual and predicted numbers of people choosing each alternative are routinely reported as summary statistics.

5. George A. Akerlof and Brian G. M. Main, "Unemployment Spells and Unemployment Experience," Division of Research and Statistics, Special Studies Paper 123 (Board of Governors of the Federal Reserve System, October 1978); Robert Lerman, Burt Barnow, and Phillip Moss, "Concepts and Measures of Structural Unemployment," Technical Analysis Paper 64 (Department of Labor, Office of the Assistant Secretary for Policy, Evaluation and Research, March 1979); and Kim B. Clark and Lawrence H. Summers, "Labor Market Dynamics and Unemployment: A Reconsideration," BPEA, 1:1979, pp. 13-60. 
Table 1. Comparisons of Median Wage and Salary Income, by Race and Work Experience, 1963-78

\begin{tabular}{cccccc}
\hline & \multicolumn{2}{c}{ Ratio of blacks to whites } & & \multicolumn{2}{c}{ Ratio of nonwhites to whites } \\
\cline { 2 - 3 } \cline { 5 - 6 } Year & $\begin{array}{c}\text { Full-year, full- } \\
\text { time } \text { workers }\end{array}$ & All workers & & $\begin{array}{c}\text { Full-year, full- } \\
\text { time workers }\end{array}$ & All workers \\
\hline 1963 & n.a. & n.a. & & 0.654 & 0.568 \\
1964 & n.a. & n.a. & & 0.660 & 0.590 \\
1965 & n.a. & n.a. & & 0.638 & 0.567 \\
1966 & n.a. & n.a. & & 0.632 & 0.594 \\
1967 & n.a. & n.a. & & 0.675 & 0.639 \\
1968 & n.a. & n.a. & & 0.699 & 0.664 \\
1969 & n.a. & n.a. & & 0.694 & 0.666 \\
1970 & n.a. & n.a. & & 0.704 & 0.664 \\
1971 & n.a. & n.a. & & 0.707 & 0.673 \\
1972 & n.a. & n.a. & & 0.700 & 0.681 \\
1973 & n.a. & n.a. & & 0.719 & 0.695 \\
1974 & n.a. & n.a. & & 0.736 & 0.709 \\
1975 & 0.747 & 0.720 & & 0.769 & 0.734 \\
1976 & 0.729 & 0.686 & & 0.746 & 0.700 \\
1977 & 0.697 & 0.684 & 0.726 & 0.705 \\
1978 & 0.771 & 0.685 & 0.796 & 0.715 \\
\hline
\end{tabular}

Source: U.S. Bureau of the Census, Current Population Reports, series P-60, no. 123, Money Income of Fanilies and Persons in the United States: 1978 (U.S. Government Printing Office, 1980), and preceding issues.

a. The sample is restricted to males aged fourteen to sixty-five. Data for blacks were not reported separately until 1975 .

n.a. Not a vailable.

data in the March supplement to the Current Population Survey and is published for all workers and for full-year, full-time workers, subdivided by race and sex. In these data a worker is an individual between the ages of fourteen and sixty-five who was employed as a wage and salary worker at the time of the CPS March interview and had positive wage and salary income for the previous year.

Table 1 presents the ratio of median wage and salary income (hereafter wage income) for nonwhite males to that of white males for the 1963-78 period. The wage-income ratios for full-year, full-time workers show a reasonably consistent pattern of increase, ranging from 0.654 in 1963 to 0.796 by 1978 . The same ratio for all workers follows a slightly more erratic pattern: it rises from 0.568 in 1963 to 0.734 in 1975 , and then levels off to 0.715 in 1978 . The ratios based on the wage income of black males, available after 1974, suggest a similar pattern at slightly 
lower levels. This general pattern of increase forms the basis for economists' arguments of earnings convergence. ${ }^{6}$

These census statistics on median incornes fail to include people who have no wage income during the year. Some people will report no wage income for reasons that have little to do with economic welfare: young students, retired individuals, farmers, or the self-employed who receive income from sources other than wages. But besides these reasons, some people have no wage income because they did not work at all during the year. Models of turnover in the labor market predict that the number of such people should be small; and within this number, many people report themselves as disabled. But the rapid increase in self-reported disabilities suggests that many disabled workers may actually be discouraged workers. ${ }^{7}$ Moreover, there is no reason to believe a priori that such disabilities are more concentrated among black males than among white males, or that the inclusion of these "zero" observations in the wageincome distribution should change the wage-income ratios for blacks and whites. ${ }^{8}$ The exclusion in the statistics of individuals who were not working at the time of the March interview (even though they had wage income in the previous year) raises similar issues.

Table 2 presents black-white (rather than nonwhite-white) ratios of median wage income from a sample modified in the following ways: the sample is restricted to people aged twenty to fifty-five, which excludes very young workers and potential retirees; students are excluded; people with farm income or those with self-employment income-potential sub-

6. Several of the articles referred to above (Freeman's "Changes in the Labor Market" and Smith and Welch's "Race Differences in Earnings") contain data only through 1975 and thus exclude the post-1975 turndown in the series for all workers.

7. See, for example, John C. Hambor, "Unemployment and Disability: An Econometric Analysis with Time Series Data," Office of Research and Statistics, Staff Paper 20 (U.S. Department of Health, Education, and Welfare, Social Security Administration, January 1975). In 1978 about 60 percent of both black and white males who reported zero wage income said they were disabled, while 12 percent of white males and 16 percent of black males reported they were unable to find work. The remainder reported they were caring for family or were out of the labor force for other reasons.

8. Butler and Heckman speculate on the effect of such zeros but their data preclude them from investigating the problem directly. They demonstrate, in effect, a partial correlation between the relative decline of average, annual black labor force participation rates and the relative increase of black median earnings. But they cannot say whether numbers of persons with zero annual earnings has actually increased. See Butler and Heckman, "The Government's Impact." 


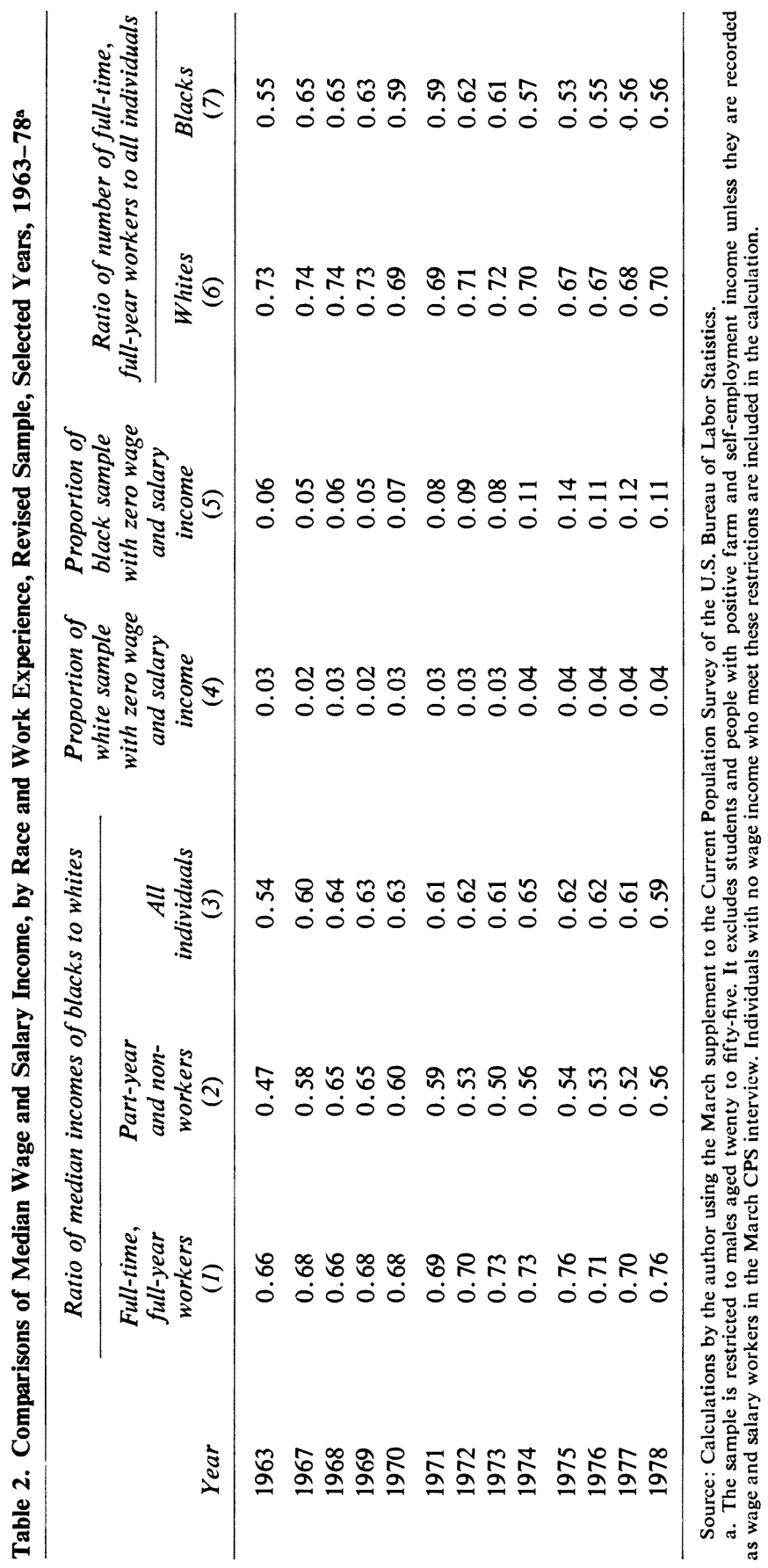


stitutes for wage income-are excluded from the sample; people who have zero wage income but who meet the above restrictions are retained. ${ }^{9}$

Column 1 in the table shows the ratios for full-year workers. Although these ratios are based on a slightly different age range than the ratios in table 1 , they should be unaffected by the inclusion of people with zero wage income. This is, in fact, the case; the ratio in table 2 shows the same convergent trends for full-year workers as those in table 1.

Column 3 contains median wage-income ratios for the entire sample, ratios that may be influenced by including persons with zero wage income. In fact, sharp differences between tables 1 and 2 do emerge. Both tables show an increase from about 0.55 to 0.62 between 1963 and 1967 . But, as noted above, the census series in table 1 continues a slow rise to 0.734 in 1975 , thereafter falling to 0.715 . By contrast, the revised series in table 2 shows much less progress-rising to 0.65 in 1974 and then declining to 0.59 in 1978. Thus when the census calculations are expanded to include persons who report no wage income, the wage-income ratio for blacks and whites shows about one-third of the progress normally reported.

The statistics in table 2 were designed to correspond as closely as possible to the standard census wage-income series while including meaningful observations of persons reporting no wage income. Annual wage income, of course, involves wage rates and hours of employment. Nonetheless, the data in table 2 offer some evidence in support of the split in the black employment distribution. The growing proportion of blacks reporting no wage income is certainly consistent with such a split, suggesting an increasing "lower tail" of the distribution. The greater parity of black and white full-year workers is also consistent because the parity appears to be due in part to a declining portion of black workers who are full-year workers (the last two columns in the table). The data there show that the proportion of full-year workers among both blacks and whites

9. Although the zero observations are in the basic data, they are excluded from official median tabulations. Incorporating these zero observations into a revised median implicitly assumes the zeros arise from involuntary behavior. If one believed that people were out of the labor force voluntarily, each zero would be replaced by the estimated wage income people could earn if they accepted available jobs. Note, however, that a similar problem arises in existing census statistics with regard to part-year workers: their wage income is tabulated as reported, and no attempt is made to estimate what those workers could make if they worked during the entire year. 
fluctuates greatly with aggregate demand, but the proportion for blacks after 1967 appears to demonstrate a weak, negative trend.

In summary, the revision of the standard earnings series produces evidence that is at least consistent with a growing split in the distribution of the employment experience of black males. I now turn to a more direct investigation of employment.

\section{A Queue Theory Model of Employment Probabilities}

Rather than focus on an individual's employment status at a given time, I examine the individual's ex ante probability of employment. This probability provides a convenient index that is both continuous and without transient variation. My approach to this probability differs from standard Markov chain turnover analysis. Recent work by Akerlof and Main, Clark and Summers, and others shows that typical labor market histories are far more stable than Markov chain models predict. Even when such a model controls for an individual's age, education, and other observable characteristics, it overpredicts the probability that the individual has relatively little unemployment, and underpredicts the probability the individual has either no unemployment or a great deal of unemployment. ${ }^{10}$ This finding suggests that any model of the labor market, Markovian or otherwise, must deal with heterogeneity deriving from unobserved as well as observed characteristics. More generally, the finding suggests that a model can accurately describe labor market experience without excessive attention to employment turnover. This means the Markov chain's nine transition probabilities can be collapsed into something more compact.

One such compact model is suggested by the work of Lerman, Barnow, and Moss. ${ }^{11}$ In that work, the authors present calculations that underline the near-term stability of individuals' employment history. A variation of those calculations appears in table 3 , in which employment status in March is cross-tabulated by work history in the previous year. The sample includes all males except students but is restricted to those aged twenty to forty years in order to include only males who, in 1978, had spent most of their working life after the beginning of the civil rights movement.

10. See Akerlof and Main, "Unemployment Spells and Unemployment Experience," and Clark and Summers, "Labor Market Dynamics and Unemployment," particularly their simulations reported on pp. 43-46.

11. See Lerman, Barnow, and Moss, "Concepts and Measures of Structural Unemployment," p. 23. 
Data shown are for 1963-64, 1971-72, and 1977-78, three pairs of years that were roughly similar in their aggregate unemployment patterns. ${ }^{12}$

The data show that people who were employed in March typically worked most of the previous year, had little unemployment in the previous year, and few had multiple spells of unemployment. By contrast, people who were unemployed in March worked a little more than half of the previous year, experienced ten to fifteen weeks of unemployment, and had a one-in-four chance of multiple spells of unemployment. In most cases, those out of the labor force in March were typically out of the labor force for most of the previous year with little chance of multiple spells of unemployment. These patterns are quite stable over time with one exception: being out of the labor force appears to be an increasingly permanent status for some black males-those who were out of the labor force in March 1964 averaged twenty-four weeks in the labor force in 1963. But black males out of the labor force in March 1978 averaged only nine weeks in the labor force in 1977.

The stable patterns in table 3 suggest a stylized model in which individuals can be ordered, or ranked, by an index of their prospects in the labor market. Generally individuals with the best prospects will be employed; those with somewhat poorer prospects will fluctuate between employment and unemployment; those with still lower prospects will fluctuate between unemployment and being out of the labor force; while individuals with the lowest prospects will be out of the labor force altogether. This kind of model would not be a good description of women or teenagers, many of whom have excellent employment prospects but are out of the labor force by choice. The ordering does provide a good description of prime-age males, the focus of this paper. Such a model is reminiscent of the queue theory of employment, the predecessor of Markovian theory. ${ }^{13}$

12. For example, the unemployment rates for white males aged thirty-five to forty-four were 2.9 and 2.5 percent in 1963 and 1964, respectively; 2.9 and 2.5 percent in 1971 and 1972; and 3.1 and 2.5 percent in 1977 and 1978. See Employment and Training Report of the President, 1979, table A-21.

13. Thurow describes the queue theory as follows: "According to the queue theory of the labor market workers are arrayed along a continuum in order of their desirability to employers. Employers choose their workers from as far up the queue as possible, but as the demand for labor expands, the dividing line between employed and unemployed shifts closer to the lower end. ... Employment expands when aggregate demand expands, and contracts when demand contracts; the popular phrase is 'first fired; last hired.' "See Lester C. Thurow, Poverty and Discrimination (Brookings Institution, 1969), pp. 48-49. 


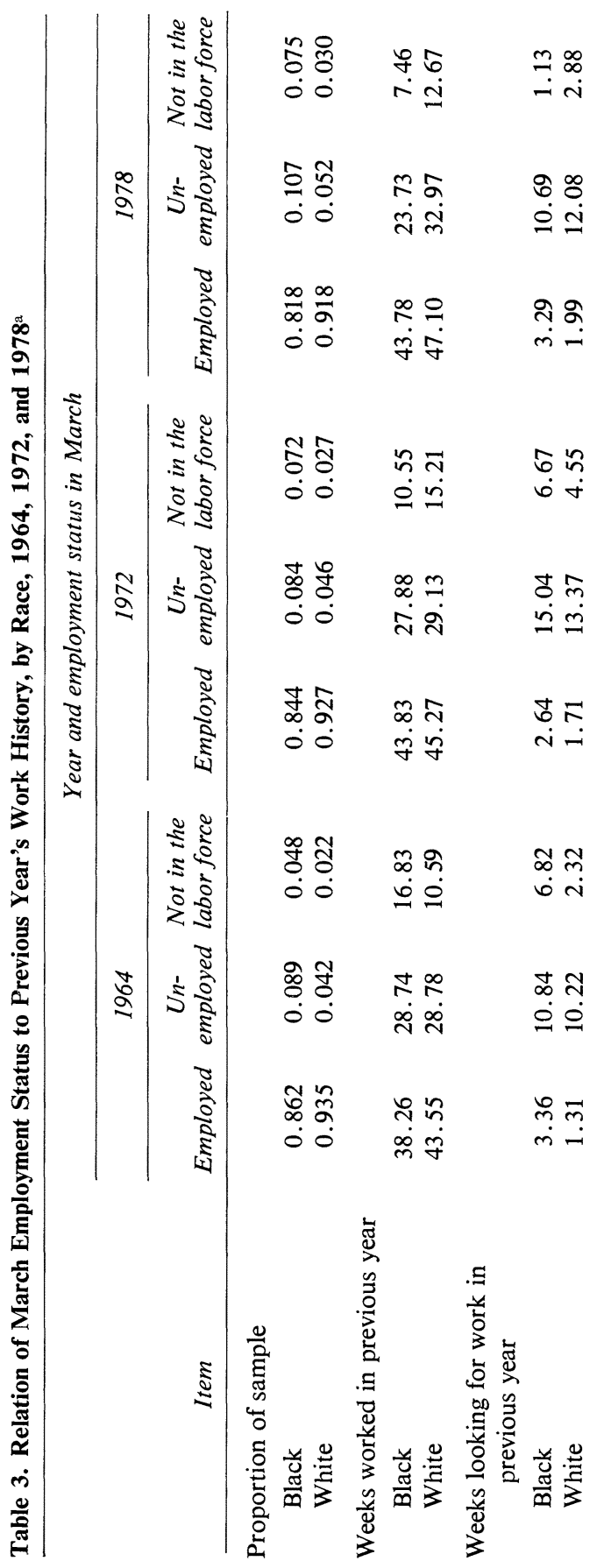




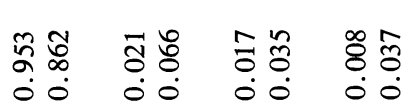

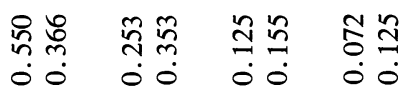

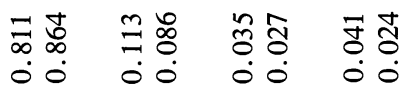

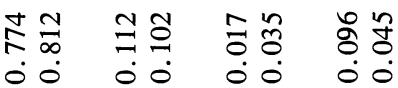

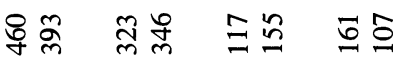

०० $0 \dot{0}$ :

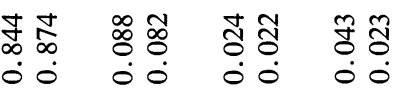

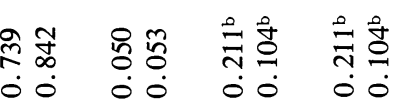

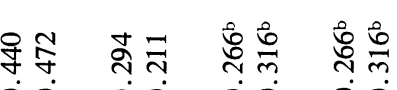

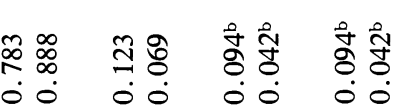

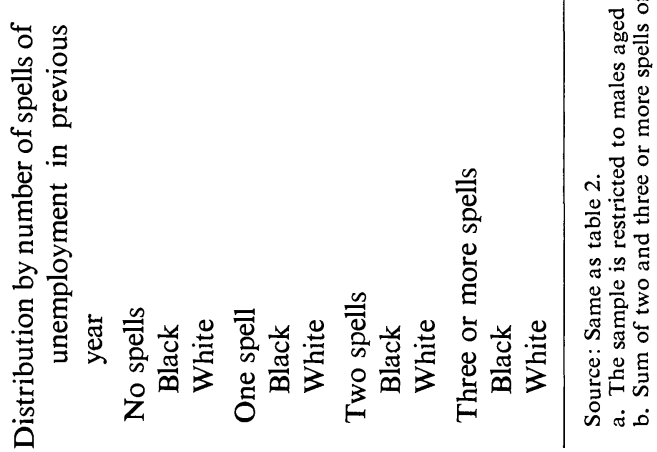


To formalize the model, a scalar index of an individual's prospects for current employment, $E_{i t}$, is related to the long-run prospects, $\bar{E}_{i}$, and a random error, $\epsilon_{i t}$, in much the same way that current income is related to permanent income:

$$
E_{i t}=\bar{E}_{i}+\epsilon_{i t},
$$

where $\epsilon_{i t}$ is normally distributed with zero mean and standard deviation $\sigma_{\epsilon}$, and is potentially serially correlated. ${ }^{14}$ Long-run prospects of employment are given by

$$
\bar{E}_{i}=\beta X_{i}+\lambda_{i},
$$

where $X_{i}$ is a vector of standard regressors including age, education, marital status, place of residence, income of other household members, and so on; and $\lambda_{i}$ is a term describing the impact of stable, unobserved characteristics, surrogates for which are the independent variables, weeks worked in the previous year and weeks spent looking for work in the previous year. Combining these two equations yields

$$
E_{i t}=\beta X_{i}+\lambda_{i}+\epsilon_{i t} .
$$

Note that while $E_{i t}$ is here explained only by the characteristics of individuals, a more complete model would also contain characteristics of demand in the individual's labor market, including the extent of racial discrimination.

By itself, $E_{i t}$ is an arbitrary index. To relate this index to observable outcomes, two threshold variables, $\mu_{1}$ and $\mu_{2}$, are defined as follows:

(2a) $\quad E_{i t}<\mu_{1}$

(2b) $\mu_{1} \leq E_{i t}<\mu_{2}$

(2c) $\mu_{2} \leq E_{i t}$ if the individual is not in the labor force in month $t$

The two thresholds, $\mu_{1}$ and $\mu_{2}$, like the vector of coefficients, $\beta$, are parameters to be estimated from the data. Together they lend precision to

14. Because this paper deals only with cross-sectional data sets, I do not discuss serial correlation further. But joint estimation of a serial correlation parameter with the other parameters permits this "state probability" model to give fairly good approximations to observed month-to-month Markovian flows. See Frank Levy, "Labor Force Dynamics and the Distribution of Employability," Working Paper 126902 (Urban Institute, January 1980), section IV, pp. 17-30. 
the description of the employment queue underlying table 3. In particular, estimates of $\beta, \mu_{1}, \mu_{2}$, and $\sigma_{\epsilon}$ are sufficient to calculate an individual's monthly probabilities of employment, unemployment, and being out of the labor force, as follows:

$$
\begin{aligned}
p_{i}^{E} & =1-F_{n}\left(\frac{\mu_{2}-\bar{E}_{i}}{\sigma_{\epsilon}}\right) \\
p_{i}^{U} & =F_{n}\left(\frac{\mu_{2}-\bar{E}_{i}}{\sigma_{\epsilon}}\right)-F_{n}\left(\frac{\mu_{1}-\bar{E}_{i}}{\sigma_{\epsilon}}\right) \\
p_{i}^{N L F} & =F_{n}\left(\frac{\mu_{1}-\bar{E}_{i}}{\sigma_{\epsilon}}\right),
\end{aligned}
$$

where $F_{n}$ is the cumulative normal distribution. The model just described can be estimated using $N$-chotomous or "ordered" probit. ${ }^{15}$

It is apparent that two of the three parameters, $\mu_{1}, \mu_{2}$, and $\sigma_{\epsilon}$, can be chosen arbitrarily. Here, to simplify a comparison of the status of black and white males in either 1964 or 1978 , the estimated equations are normalized so that $\mu_{2}^{\text {black }}=\mu_{2}^{\text {white }}=0$. This means a black or white male with a predicted employability of $\bar{E}_{i}=0$ has a probability of one-half of being employed. And, because $\sigma_{\epsilon}$ is normalized and is the same for blacks and whites (1.0), a black or a white male with equal values of $\bar{E}_{i}$

15. $N$-chotomous probit is designed to analyze ordered (rather than disjoint) qualitative outcomes. A typical example arises in data from a political poll from which there is a set of background characteristics for each respondent, $X_{l}$, and the respondent's rating of, say, the president's performance on a scale ranging from $A$ (outstanding) to $\mathrm{F}$ (poor). The estimator assumes the existence of an unobserved, continuous variable, $y_{\imath}=\beta^{\prime} X_{i}+\epsilon_{i}$, where $\epsilon_{\imath}$ is assumed to be normally distributed with mean zero and constant variance, $\sigma^{2}$, across individuals. The estimator also assumes the existence of, in this case, five thresholds, $\mu_{1}=\mu_{5}$, such that if $y_{1}$ is less than the first threshold, the respondent will give the president the lowest rating; if $y_{\text {, }}$ lies between the first and second threshold, the respondent will give the president the next lowest rating, and so on. Richard McKelvey and William Zavoina show that it is straightforward to form and maximize the likelihood function of the coefficients, $\beta$, the thresholds, $\mu_{i}$, and the variance $\sigma^{2}$. Because the problem is a probit and because it is based on ordinal data, maximizing the likelihood function does not yield a unique set of parameters. Normalizing assumptions are required and the two usually adopted are $\mu_{1}=0$ and $\sigma^{2}=1$. In this paper it is more convenient to set $\mu_{2}=0$ and estimate $\mu_{1}$, a change explained below. See Richard D. McKelvey and William Zavoina, "A Statistical Model for the Analysis of Ordinal Level Dependent Variables," Journal of Mathematical Sociology, vol. 4, no. 1 (1975), pp. 103-20. 
will have equal ex ante probabilities of employment. ${ }^{16}$ Because both years are normalized in the same way, the estimated coefficients in all equations can be compared directly. Because macroeconomic conditions were comparable in the two years, differences in the equations can be assumed to arise from the personal characteristics that are identified with employability.

This model provides a useful descriptive tool. First, the vector of the estimated coefficients, $\hat{\beta}$, is applied to each person in the sample to construct $\hat{E}_{i}$, an estimate of the individual's long-run employment prospects, $\bar{E}_{i}$. The $\hat{E}_{1}$ are then arranged in a frequency distribution (along with the estimated $\mu_{1}$ and $\mu_{2}$ ) to illustrate the distribution of employment prospects in a group. It is then possible to take ranges or segments of this frequency distribution to see how the mean characteristics within each segment compare. Moreover, it is possible to compare the frequency distributions for different racial groups or years (with similar macro conditions) to obtain an understanding of changes in employment prospects.

Table 4 contains estimates of the model for black and white males aged twenty to forty, using data for March 1964 and March 1978. The independent variables are self-explanatory with three exceptions: rotation group is a dichotomous variable set to 1 if the person is in the first or fifth interview month of the CPS, a correction for rotation group bias. ${ }^{17}$ Welfare in 1964 is set to 1 if the individual's household receives transfers, a limitation imposed by the coding used in that year. (In 1978 the variable refers to Aid to Families with Dependent Children and "other welfare" only.) Other household income refers to total income received in the individual's household, excluding own earned income. The variable includes transfers, property income, the earnings of other household members, and so on. There is no reason to suppose this variable would change or fall in response to a change in an individual's own earnings.

16. Note, however, that when $\mu_{2}^{\text {black }}$ and $\mu_{2}^{\text {white }}$ are defined to be zero, the estimated parameter, $\mu_{1}^{\text {black }}$, is less than $\mu_{1}^{\text {white }}$ in both 1964 and 1978. As mentioned above, $\mu_{1}$ is the dividing line between being unemployed and being out of the labor force. Thus black males with the same probability of being employed as white males have a higher probability of being unemployed and a lower possibility of being out of the labor force.

17. For a discussion of rotation group bias, see Ralph E. Smith and Jean E. Vanski, "Gross Flows Data: The Neglected Data Base," in National Commission on Employment and Unemployment Statistics, Counting the Labor Force, Appendix, vol 2: Data Collection, Processing and Presentation: National and Local (U.S. Government Printing Office, 1979), pp. 131-50. 
As noted above, weeks worked in the previous year and weeks spent looking for work in the previous year are included as surrogates for $\lambda_{l}$, the impact of unobserved characteristics.

The most obvious difference in coefficients between 1964 and 1978 is the change in the sign on the variable for weeks spent looking for work in the previous year, a variable that is significantly negative in 1964 and significantly positive in 1978 for both black and white males. This changing sign reflects a change in the labor markets over the intervening period. In 1964 relatively few persons were out of the labor force on a permanent basis. When the model ranked people by their employment prospects, the ranking suggested most people should be either employed or unemployed (but not out of the labor force). In this context, weeks spent looking for work in the previous year was a negative factor, indicating that individuals would be in the lower of the two, de facto, categories of labor market status. In 1978 being out of the labor force was a permanent status for a growing number of individuals, and so the model was predicting for three long-run statuses rather than two. In this context, weeks spent looking for work in the previous year was a sign of some labor force attachment and thus acted as a positive factor indicating the individual should not be ranked in the lowest labor market status.

A related but more general change is the extent to which "sorting" has increased among whites and even more among blacks over time. Sorting refers to the impact of an individual's characteristics (including work history) upon employment prospects. As mentioned above, under the normalization used here, a given value of the index, $\hat{E}_{1}$, translates into the same probability of employment for both black and white males in 1964 and 1978. Correspondingly, the extent of sorting in a particular equation can be gauged by the degree to which an individual's value of $\hat{E}_{i}$ is sensitive to changes in that individual's characteristics. An examination of the estimated equation for black males in 1964 in table 4 shows that the value of $\hat{E}_{i}$ is relatively insensitive to most important characteristics: its coefficient for years of education is about one-third of the corresponding coefficient for whites; its coefficient for weeks worked in the previous year is about two-thirds of the corresponding coefficient for whites. By 1978 these black-white coefficient differences had narrowed greatly, and the coefficients, particularly for past weeks worked, had grown substantially larger. These changes suggest that all categories of labor market status-not just being out of the labor force-are becom- 
Table 4. Estimates of the Employability Model for Blacks and Whites, 1964-78 ${ }^{\text {a }}$

\begin{tabular}{|c|c|c|c|c|}
\hline \multirow{2}{*}{$\begin{array}{l}\text { Independent variable } \\
\text { and threshold parameter }\end{array}$} & \multicolumn{2}{|c|}{1964} & \multicolumn{2}{|c|}{1978} \\
\hline & Blacks & Whites & Blacks & Whites \\
\hline Rotation group ${ }^{b}$ & $\begin{array}{c}0.017 \\
(0.144)\end{array}$ & $\begin{array}{c}0.113 \\
(1.441)\end{array}$ & $\begin{array}{c}0.149 \\
(1.624)\end{array}$ & $\begin{array}{r}-0.050 \\
(0.680)\end{array}$ \\
\hline Central Cityb & $\begin{aligned}-0.175 \\
(1.438)\end{aligned}$ & $\begin{array}{c}-0.071 \\
(0.925)\end{array}$ & $\begin{array}{r}-0.030 \\
(0.358)\end{array}$ & $\begin{array}{c}0.068 \\
(0.883)\end{array}$ \\
\hline South $^{\mathrm{b}}$ & $\begin{array}{r}-0.233 \\
(1.901)\end{array}$ & $\begin{array}{c}0.069 \\
(0.848)\end{array}$ & $\begin{array}{c}0.181 \\
(2.131)\end{array}$ & $\begin{array}{c}-0.028 \\
(0.400)\end{array}$ \\
\hline Education $^{\mathrm{b}}$ & $\begin{array}{c}0.039 \\
(2.266)\end{array}$ & $\begin{array}{c}0.110 \\
(9.346)\end{array}$ & $\begin{array}{l}0.052 \\
(3.344)\end{array}$ & $\begin{array}{c}0.051 \\
(4.363)\end{array}$ \\
\hline $\begin{array}{l}\text { Other household income } \\
\quad \times 10^{-4}\end{array}$ & $\begin{array}{r}-0.527 \\
(1.867)\end{array}$ & $\begin{array}{c}0.138 \\
(1.199)\end{array}$ & $\begin{array}{r}-0.291 \\
(2.462)\end{array}$ & $\begin{array}{c}0.111 \\
(1.329)\end{array}$ \\
\hline $\begin{array}{l}\text { Other household income } \\
\text { squared } \times 10^{-9}\end{array}$ & $\begin{array}{c}0.277 \\
(2.019)\end{array}$ & $\begin{array}{r}-0.600 \\
(1.782)\end{array}$ & $\begin{array}{c}0.829 \\
(2.280)\end{array}$ & $\begin{array}{r}-0.342 \\
(1.504)\end{array}$ \\
\hline Income from welfare ${ }^{b}$ & $\begin{array}{l}-0.200 \\
(1.594)\end{array}$ & $\begin{array}{c}-0.416 \\
(5.426)\end{array}$ & $\begin{array}{c}-0.108 \\
(0.890)\end{array}$ & $\begin{array}{c}0.145 \\
(0.884)\end{array}$ \\
\hline $\begin{array}{l}\text { Age twenty-five or less, } \\
\text { married }^{\mathrm{b}}\end{array}$ & $\begin{array}{r}-0.085 \\
(0.443)\end{array}$ & $\begin{array}{r}-0.252 \\
(2.154)\end{array}$ & $\begin{array}{r}-0.309 \\
(1.988)\end{array}$ & $\begin{array}{r}-0.188 \\
(1.700)\end{array}$ \\
\hline $\begin{array}{l}\text { Age twenty-five or less, } \\
\text { single }^{b}\end{array}$ & $\begin{array}{c}-0.482 \\
(2.567)\end{array}$ & $\begin{array}{c}-0.425 \\
(3.312)\end{array}$ & $\begin{array}{c}-0.171 \\
(1.303)\end{array}$ & $\begin{array}{r}-0.267 \\
(2.528)\end{array}$ \\
\hline $\begin{array}{l}\text { Ages twenty-five to thirty- } \\
\text { four, married (reference } \\
\text { group) }\end{array}$ & $\begin{array}{l}\ldots \\
\ldots\end{array}$ & $\begin{array}{l}\cdots \\
\ldots\end{array}$ & $\begin{array}{l}\cdots \\
\cdots\end{array}$ & $\begin{array}{l}\cdots \\
\cdots\end{array}$ \\
\hline $\begin{array}{l}\text { Ages twenty-five to thirty- } \\
\text { four, single }\end{array}$ & $\begin{array}{r}-0.597 \\
(2.917)\end{array}$ & $\begin{array}{c}-0.363 \\
(2.495)\end{array}$ & $\begin{array}{r}-0.139 \\
(0.984)\end{array}$ & $\begin{array}{r}-0.388 \\
(3.169)\end{array}$ \\
\hline $\begin{array}{l}\text { Age thirty-four or more, } \\
\text { married }^{\mathrm{b}}\end{array}$ & $\begin{array}{c}-0.075 \\
(0.430)\end{array}$ & $\begin{array}{r}-0.090 \\
(0.838)\end{array}$ & $\begin{array}{c}0.189 \\
(1.112)\end{array}$ & $\begin{array}{c}-0.142 \\
(1.325)\end{array}$ \\
\hline $\begin{array}{l}\text { Age thirty-four or more, } \\
\text { single }^{\mathrm{b}}\end{array}$ & $\begin{array}{r}-0.395 \\
(1.798)\end{array}$ & $\begin{array}{r}-0.246 \\
(1.369)\end{array}$ & $\begin{array}{l}-0.226 \\
(1.270)\end{array}$ & $\begin{array}{r}-0.202 \\
(1.110)\end{array}$ \\
\hline Children under age $\operatorname{six}^{b}$ & $\begin{array}{c}0.167 \\
(1.253)\end{array}$ & $\begin{array}{c}0.197 \\
(2.270)\end{array}$ & $\begin{array}{c}-0.068 \\
(0.592)\end{array}$ & $\begin{array}{r}-0.200 \\
(2.271)\end{array}$ \\
\hline $\begin{array}{l}\text { Weeks worked in previous } \\
\text { year }\end{array}$ & $\begin{array}{c}0.014 \\
(5.094)\end{array}$ & $\begin{array}{c}0.022 \\
(12.918)\end{array}$ & $\begin{array}{c}0.053 \\
(24.761)\end{array}$ & $\begin{array}{c}0.058 \\
(30.925)\end{array}$ \\
\hline
\end{tabular}


Table 4 (continued)

\begin{tabular}{|c|c|c|c|c|}
\hline \multirow{2}{*}{$\begin{array}{l}\text { Independent variable } \\
\text { and threshold parameter }\end{array}$} & \multicolumn{2}{|c|}{1964} & \multicolumn{2}{|c|}{1978} \\
\hline & Blacks & Whites & Blacks & Whites \\
\hline $\begin{array}{l}\text { Weeks looking for work } \\
\text { in previous year }\end{array}$ & $\begin{array}{c}-0.015 \\
(2.733)\end{array}$ & $\begin{array}{c}-0.022 \\
(5.229)\end{array}$ & $\begin{array}{c}0.023 \\
(8.095)\end{array}$ & $\begin{array}{c}0.020 \\
(6.673)\end{array}$ \\
\hline Constant & $\begin{array}{c}0.866 \\
(5.553)\end{array}$ & $\begin{array}{r}-0.206 \\
(2.453)\end{array}$ & $\begin{array}{r}-1.628 \\
(3.153)\end{array}$ & $\begin{array}{r}-1.496 \\
(3.829)\end{array}$ \\
\hline$\mu_{1}$ & $\begin{array}{l}-0.681 \\
(9.751)\end{array}$ & $\begin{array}{l}-0.656 \\
(13.677)\end{array}$ & $\begin{array}{l}-0.801 \\
(14.916)\end{array}$ & $\begin{array}{l}-0.721 \\
(15.808)\end{array}$ \\
\hline Addenda & & & & \\
\hline$\mu_{2}$ & 0 & 0 & 0 & 0 \\
\hline Sample size & 928 & 3,996 & 1,788 & 3,965 \\
\hline $\begin{array}{l}\text { Proportion of labor market } \\
\text { states correctly predicted }\end{array}$ & 0.865 & 0.935 & 0.853 & 0.915 \\
\hline
\end{tabular}

Source: Same as table 2.

a. The model was estimated using the $N$-chotomous probit technique. The dependent variable is a three-state qualitative variable assuming the following values: highest, if the individual is employed in March; middle, if unemployed in March; and lowest, if out of the labor force in March. For a more complete explanation see Richard D. McKelvey and William Zavoina, "A Statistical Model for the Analysis of Ordinal Level Dependent Variables,"Journal of Mathematical Sociology, vol. 4, no. 1 (1975), pp. 103-20.

Rotation group is a dichotomous variable set to 1 if the person is in the first or fifth interview month to correct for bias. Welfare is set to 1 if the individual's household receives income from transfers; in 1978 it refers only to Aid to Families with Dependent Children and "other welfare." Other household income refers to total income received in the previous year in the household, excluding the individual's own earnings. Weeks worked in previous year and weeks looking for work in previous year are included as surrogates for impact of unobserved characteristics. The $\mu_{1}$ and $\mu_{2}$ terms are thresholds that separate those out of the labor force from the unemployed and the unemployed from the employed, respectively. The numbers in parentheses are asymptotic $t$-statistics.

b. Dichotomous variable.

c. The sample is restricted to males aged twenty to forty. Observations were reweighted to correct for sampling probabilities.

ing more permanent over time. The greater differentiation in the market among workers, implicit in this growing permanence, particularly affects blacks; in the early 1960s there was little evidence of such differentiation among black workers.

A final difference in coefficients appears in the influence of place of residence in the prospects for employment of blacks. In 1964 a residence in the southern United States caused a black male's value of $\hat{E}_{i}$ to decrease by 0.233 , a decline equivalent to that produced by having a sixthgrade rather than a twelfth-grade education; by 1978 a southern residence increased the value by 0.181 , a gain equivalent to that caused by three additional years of education. 
Figure 1. Estimated Frequency Distributions of Employability for Blacks and Whites, 1964 ${ }^{a}$

\section{Percent of population}

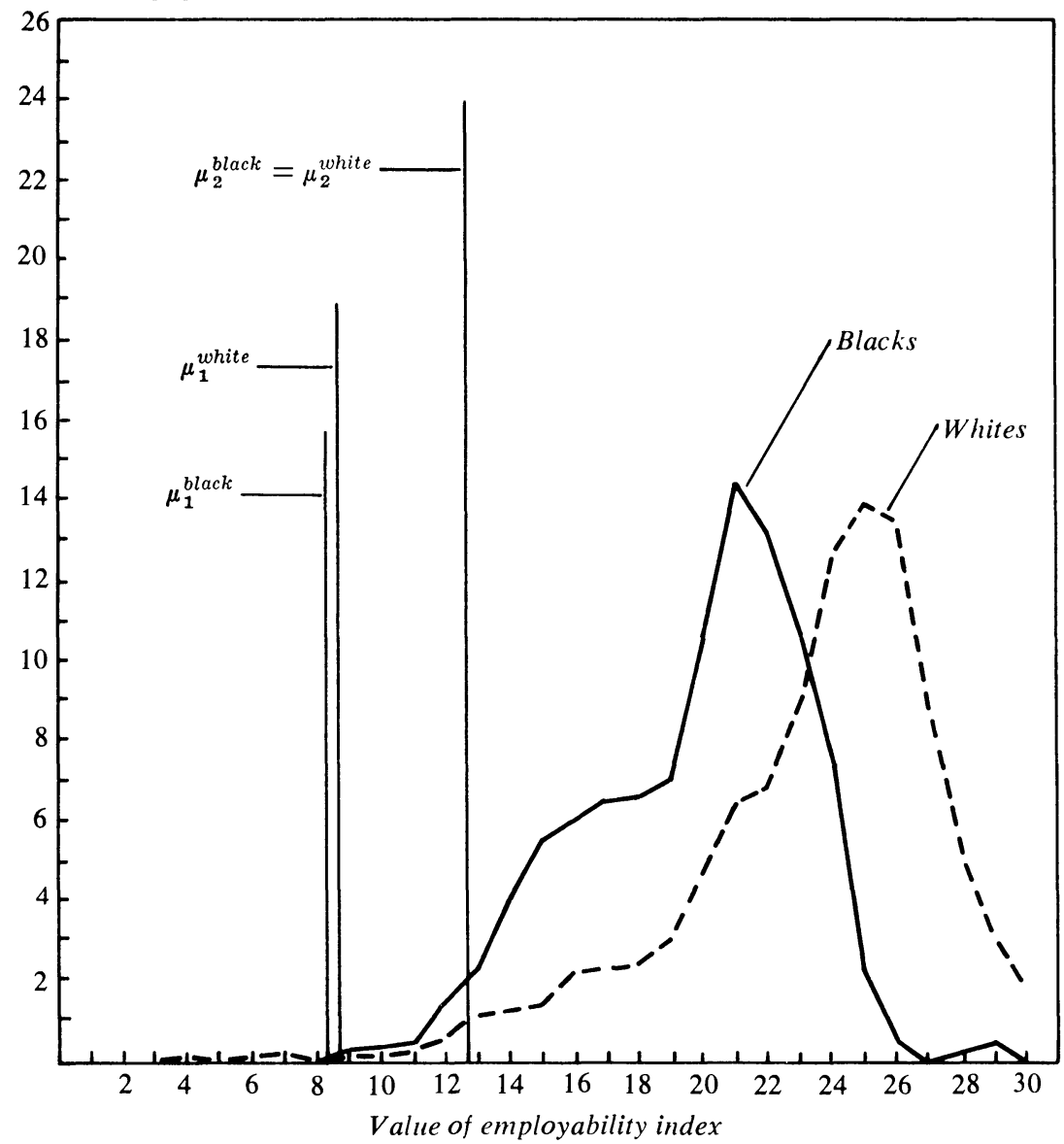

Source: Calculations by the author based on equations for 1964.

a. The $\mu_{1}$ and $\mu_{2}$ terms are the thresholds that separate those out of the labor force from the unemployed and the unemployed from the employed, respectively. The values shown are the estimates of the model. Data are restricted to males aged twenty to forty, excluding students.

The four estimated equations are translated into frequency distributions of estimated employment prospects, $\hat{E}_{i}$, in figures 1 and 2 for 1964 and 1978, respectively. For clarity, the index is transformed so that all values are positive. Table 5 contains the indexes for the two years, and for each index value the ex ante probability of employment (equal for blacks and whites) and the ex ante probability of unemployment (not 
Figure 2. Estimated Frequency Distribution of Employability for Blacks and Whites, 1978

\section{Percent of population}

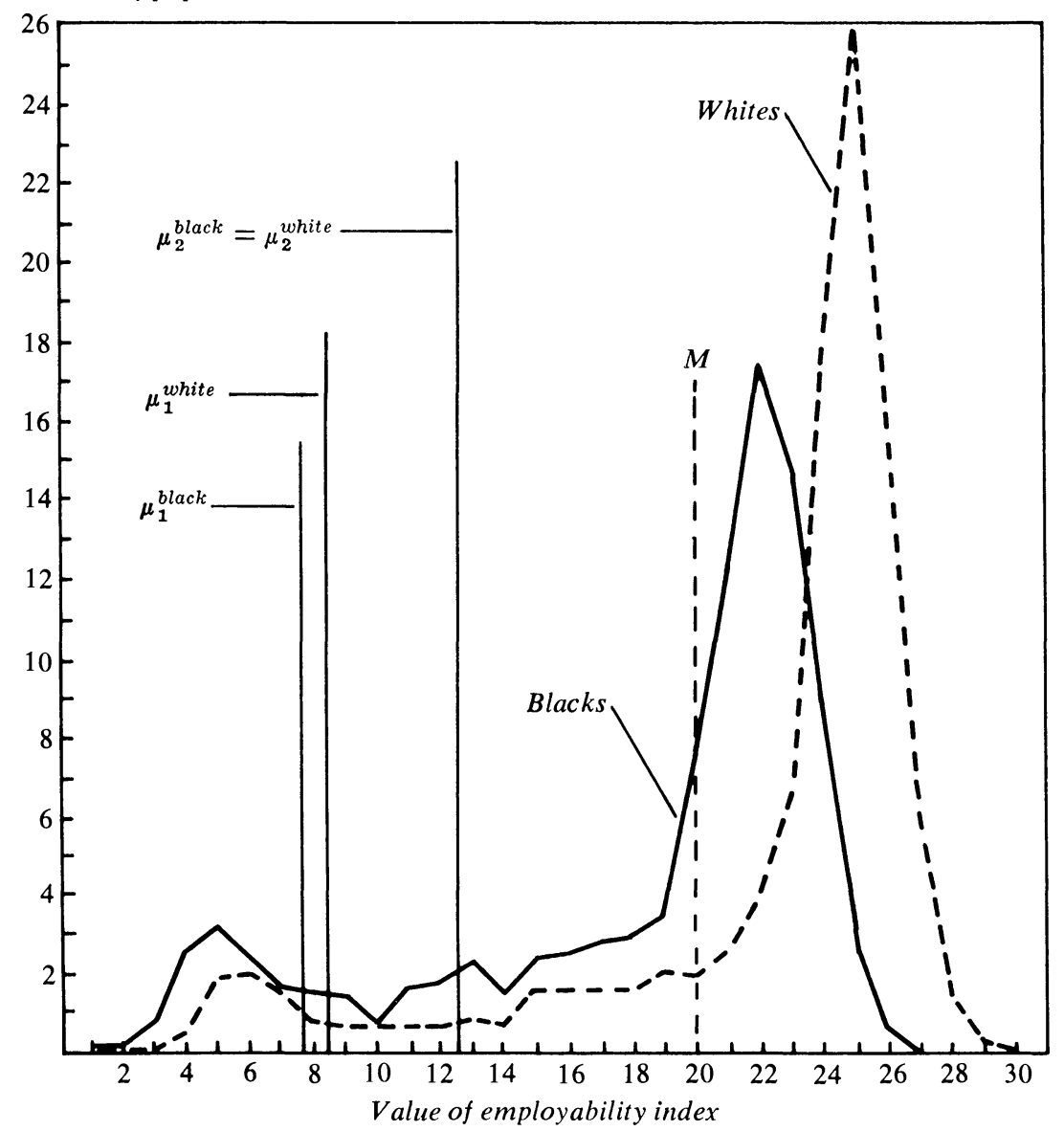

Source: Calculations by the author based on equations for 1978.

a. See figure 1 , note a. The $M$ term is an arbitrary division of the employed.

necessarily equal for blacks and whites).$^{18}$ Included in each figure are the estimated values of $\mu_{1}$ and $\mu_{2}$. The 1978 distribution shows a dotted line, $M$, an arbitrary division of the employed that is used below to obtain a sharper picture of their characteristics.

Table 6 contains cumulative tabulations of the frequency distributions

18. Again, this follows from the fact that $\mu_{1}^{\text {black }} \neq \mu_{1}^{\text {white }}$. 
Table 5. Index of Employability, Probabilities of Employment and of Unemployment for Blacks and Whites, 1964 and $1978^{\mathrm{a}}$

\begin{tabular}{|c|c|c|c|c|c|}
\hline \multirow{3}{*}{$\begin{array}{c}\text { Value of } \\
\text { index of } \\
\text { employ- } \\
\text { ability, } \\
\hat{E}_{i}\end{array}$} & \multirow{3}{*}{$\begin{array}{c}\text { Probability } \\
\text { of } \\
\text { employment, } \\
p^{E}\end{array}$} & \multicolumn{4}{|c|}{ Probability of unemployment } \\
\hline & & \multicolumn{2}{|c|}{1964} & \multicolumn{2}{|c|}{1978} \\
\hline & & Blacks & Whites & Blacks & Whites \\
\hline 1 & 0.03 & 0.08 & 0.01 & 0.11 & 0.10 \\
\hline 2 & 0.04 & 0.10 & 0.09 & 0.15 & 0.12 \\
\hline 3 & 0.06 & 0.15 & 0.15 & 0.17 & 0.15 \\
\hline 4 & 0.09 & 0.16 & 0.15 & 0.20 & 0.18 \\
\hline 5 & 0.12 & 0.18 & 0.17 & 0.23 & 0.20 \\
\hline 6 & 0.15 & 0.22 & 0.21 & 0.26 & 0.23 \\
\hline 7 & 0.19 & 0.24 & 0.22 & 0.28 & 0.25 \\
\hline 8 & 0.24 & 0.26 & 0.24 & 0.30 & 0.27 \\
\hline 9 & 0.30 & 0.27 & 0.25 & 0.31 & 0.28 \\
\hline 10 & 0.36 & 0.27 & 0.25 & 0.31 & 0.28 \\
\hline 11 & 0.42 & 0.26 & 0.23 & 0.30 & 0.28 \\
\hline 12 & 0.49 & 0.24 & 0.23 & 0.29 & 0.27 \\
\hline 13 & 0.55 & 0.24 & 0.23 & 0.27 & 0.25 \\
\hline 14 & 0.62 & 0.21 & 0.21 & 0.25 & 0.23 \\
\hline 15 & 0.68 & 0.19 & 0.18 & 0.22 & 0.20 \\
\hline 16 & 0.74 & 0.16 & 0.15 & 0.19 & 0.18 \\
\hline 17 & 0.79 & 0.13 & 0.13 & 0.16 & 0.15 \\
\hline 18 & 0.84 & 0.10 & 0.10 & 0.13 & 0.12 \\
\hline 19 & 0.87 & 0.10 & 0.07 & 0.10 & 0.10 \\
\hline 20 & 0.90 & 0.08 & 0.05 & 0.08 & 0.07 \\
\hline 21 & 0.93 & 0.05 & 0.04 & 0.06 & 0.06 \\
\hline 22 & 0.95 & 0.04 & 0.03 & 0.04 & 0.04 \\
\hline 23 & 0.96 & 0.03 & 0.02 & 0.03 & 0.03 \\
\hline 24 & 0.98 & 0.02 & 0.01 & 0.02 & 0.02 \\
\hline 25 & 0.98 & 0.02 & 0.01 & 0.02 & 0.02 \\
\hline 26 & 0.99 & 0.01 & 0.00 & 0.01 & 0.02 \\
\hline 27 & 0.99 & 0.00 & 0.00 & 0.01 & 0.01 \\
\hline 28 & 1.00 & 0.00 & 0.00 & 0.00 & 0.01 \\
\hline 29 & 1.00 & 0.00 & 0.00 & 0.00 & 0.00 \\
\hline 30 & 1.00 & 0.00 & 0.00 & 0.00 & 0.00 \\
\hline
\end{tabular}

Source: Same as figures 1 and 2 .

a. When the equations are normalized, the estimated value of the threshold variable, $\mu_{1}$, corresponds to index values for $\hat{E}_{2}$ of 8.40 and 8.80 in 1964 and 7.90 and 8.40 in 1978 for blacks and whites, respectively. The expression $\mu_{2}^{\text {black }}=\mu_{2}^{\text {whtte }}$ corresponds to an index value of 12.70 in 1964 and 1978. The line that arbitrarily subdivides the employed in 1978, $M$, corresponds to an index value of 20.00. Data are restricted to males aged twenty to forty. 
Table 6. Comparison of Cumulative Distribution of Employability for Black and White Males, 1964 and $1978^{a}$

\begin{tabular}{|c|c|c|c|c|c|}
\hline \multicolumn{3}{|c|}{1964} & \multicolumn{3}{|c|}{1978} \\
\hline $\begin{array}{l}\text { Probability of } \\
\text { employment, } \\
p^{E}\end{array}$ & $\begin{array}{l}\text { Proportion } \\
\text { of blacks } \\
\text { below } p^{E}\end{array}$ & $\begin{array}{l}\text { Proportion } \\
\text { of whites } \\
\text { below } p^{E}\end{array}$ & $\begin{array}{l}\text { Probability of } \\
\text { employment, } \\
p^{E}\end{array}$ & $\begin{array}{l}\text { Proportion } \\
\text { of blacks } \\
\text { below } p^{E}\end{array}$ & $\begin{array}{l}\text { Proportion } \\
\text { of whites } \\
\text { below } p^{E}\end{array}$ \\
\hline 0.581 & 0.05 & 0.025 & 0.113 & 0.05 & 0.024 \\
\hline 0.651 & 0.10 & 0.043 & 0.196 & 0.10 & 0.050 \\
\hline 0.723 & 0.15 & 0.060 & 0.432 & 0.15 & 0.075 \\
\hline 0.786 & 0.20 & 0.084 & 0.589 & 0.20 & 0.101 \\
\hline 0.833 & 0.25 & 0.108 & 0.749 & 0.25 & 0.134 \\
\hline 0.837 & 0.30 & 0.128 & 0.823 & 0.30 & 0.165 \\
\hline 0.852 & 0.35 & 0.145 & 0.885 & 0.35 & 0.191 \\
\hline 0.870 & 0.40 & 0.161 & 0.894 & 0.40 & 0.201 \\
\hline 0.882 & 0.45 & 0.186 & 0.912 & 0.45 & 0.227 \\
\hline 0.905 & 0.50 & 0.204 & 0.936 & 0.50 & 0.243 \\
\hline 0.919 & 0.55 & 0.227 & 0.938 & 0.55 & 0.262 \\
\hline 0.932 & 0.60 & 0.248 & 0.945 & 0.60 & 0.282 \\
\hline 0.936 & 0.65 & 0.270 & 0.956 & 0.65 & 0.302 \\
\hline 0.941 & 0.70 & 0.292 & 0.964 & 0.70 & 0.323 \\
\hline 0.958 & 0.75 & 0.320 & 0.966 & 0.75 & 0.389 \\
\hline 0.965 & 0.80 & 0.348 & 0.971 & 0.80 & 0.435 \\
\hline 0.969 & 0.85 & 0.389 & 0.978 & 0.85 & 0.490 \\
\hline 0.974 & 0.90 & 0.448 & 0.985 & 0.90 & 0.629 \\
\hline 0.988 & 0.95 & 0.551 & 0.987 & 0.95 & 0.793 \\
\hline 1.000 & 1.00 & 1.000 & 1.000 & 1.00 & 1.000 \\
\hline
\end{tabular}

Source: Same as figures 1 and 2.

a. Data are restricted to males aged twenty to forty.

in figures 1 and 2. In this table, as in the two figures, the split in the black employment structure emerges. The 1964 data show a distribution of employment probabilities for black males that is well below that for whites and is relatively compressed. For example, three-quarters of all blacks had estimated employment probabilities below 0.958 , while only one-third of whites had estimated probabilities that low. At the same time, the lowest 5 percent of the distribution for black males was bounded above by an employment probability of 0.581 , a relatively high number for this low segment.

By 1978 the upper part of the distribution of black males had gained compared to that for whites. When ranked in terms of employment probabilities, the top 15 percent of black males in 1964 corresponded to the 


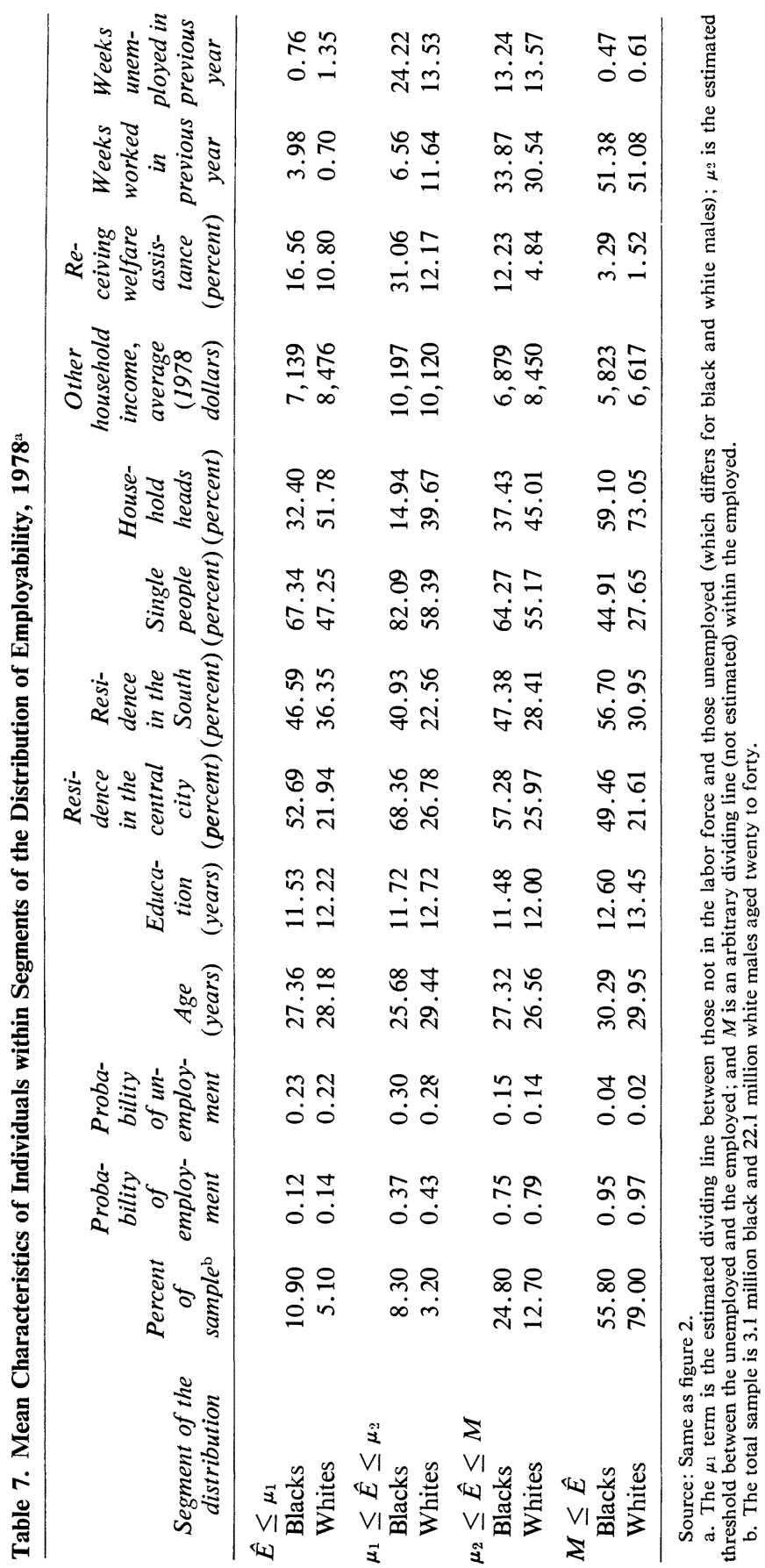


top 61 percent of white males. By 1978 the top 15 percent of black males corresponded to the top 51 percent of whites, an "overtaking" of ten percentage points. Similar gains occurred in the top quarter of the distribution of black males.

At the same time, the distribution of black males and, to a lesser extent, that of whites developed significant lower tails. By 1978 about 17 percent of the distribution of blacks had less than a 0.5 probability of employment, and the lowest 10 percent had employment probabilities of less than 0.2 . The rapid growth of the number of people with relatively few employment prospects shows up in the emergence of a secondary peak in the frequency distribution in figure 2 compared with the distribution in figure 1 .

Table 7 takes a closer look at the data that underlies this split distribution; it contains the mean characteristics of black and white males within different segments of figure 2 . In the table the black and white samples are divided into four segments: those estimated to be out of the labor force $\left(\hat{E}_{i}<\mu_{1}\right)$, those estimated to be unemployed $\left(\mu_{1} \leq \hat{E}_{i}<\mu_{2}\right)$, and two groups of employed, $\left(\mu_{2} \leq \hat{E}_{i}<M\right)$ and $\left(M \leq \hat{E}_{i}\right)$, where $M$ is the arbitrary division of the employed in figure 2 mentioned above. ${ }^{19}$

Common sense suggests there should be significant differences between people in the lowest and highest segments of the distribution. In fact, however, these differences are smaller than one might suspect in all variables except work history. The lowest segment of the distribution of black males contains about 11 percent of the sample, about 340,000 people; the highest segment contains 56 percent, or 1.7 million persons. People in the lowest segment are on average four years younger than those in the highest segment (age twenty-seven compared to thirty-one), have less education ( 11.5 years and 13 years, respectively) and are somewhat less likely to live in the southern states (47 percent and 57 percent, respectively). Differences also exist in such variables as the number of people who are single (67 percent compared to 45 percent) and the number of people who are household heads ( 32 percent and 59 percent), but the association of these variables with poor employment prospects is not surprising; there may be elements of simultaneity.

Of particular interest are the variables for other household income and proportion receiving welfare. A number of authors have speculated that

19. Again, note that in these calculations $\mu_{1}^{\text {black }} \neq \mu_{1}^{\text {white }}$. 
the declining labor force participation rate of blacks is linked to the rising availability of transfers, and that this relation should be captured by either or both of these variables. ${ }^{20}$ The data in table 7 are ambiguous on this point. They show that blacks in the lowest segment of the 1978 distribution live in households in which other income (exclusive of their own earnings) averaged $\$ 7,139$, and 17 percent of the households reported receipt of Aid to Families with Dependent Children or other welfare.

To put these numbers in perspective, note first that both numbers are lower than the corresponding numbers for the estimated unemployed individuals $\left(\mu_{1} \leq \hat{E}_{i}<\mu_{2}\right.$ ) who have significantly higher ex ante probabilities of employment. Note also that the level of other household income in the lowest segment is not much greater than the level of other household income for persons with good employment prospects $\left(\mu_{2}<\hat{E}_{i}\right)$. At the same time, preliminary tabulations suggest that the largest part of other household income, even in the lowest segment of the distribution, comes from the earnings of other household members. Thus the data suggest that people who do not work have alternative income sources (including the earnings of other family members) but the inducement effects of this other income remain unclear.

The last two columns of table 7 describe recent work history; it is here that large differences occur. Black and white males in the lowest segment of the distribution averaged less than four weeks worked in the previous year, compared to fifty-one weeks of work for men in the highest segment. This variable and the corresponding variable for weeks of unemployment are subject to two interpretations. One is that the variables correct for individual characteristics not captured by standard variables. According to this interpretation, a small number of weeks worked can reflect physical disabilities, other health problems like alcoholism, problems with literacy, and so on. Alternatively, the variables may show that people who develop a work history have an increasingly easy time finding work because work exposes an individual to future job contacts, because past work history makes an applicant attractive to a future employer, and so on. This interpretation takes the view that it is not innate individual differences but the experience of work itself that affects future employment

20. See Butler and Heckman, "The Government's Impact," and the response in Smith and Welch, "Race Differences in Earnings," p. 70, n. 12. Note that the data in the present paper do not capture the value of in-kind transfers like food stamps. 
prospects, and so people with fairly similar characteristics can, by luck or by discrimination, fall into very different careers. ${ }^{21}$

The nature of the CPS data do not permit a test between these two hypotheses. Whatever the relative importance of each, the emergence of a significant proportion of black males with both exceptionally poor employment experience and prospects of employment is a major problem. It is now quite common to criticize both the CPS and the decennial census for undercounting people with marginal attachment to work, to place of residence, and to other institutions of society. Whether or not these criticisms are correct, they should not obscure the growing number of such marginally attached males who already appear in official numbers.

One would hope that an analysis of the data would show clear differences between this group of males and other males whose prospects for employment are more promising. In fact, the differences that do exist (other than differences in recent work history) are fairly modest. These differences may obscure large differences in unobserved characteristics such as literacy and disability; alternatively, they may reflect a situation of relatively limited jobs in which discrimination and chance play a disproportionate role.

\section{Discussion}

LEVY's analysis of employment prospects was endorsed by Robert Hall as an important amendment to studies analyzing the economic performance of blacks. Hall noted that as blacks left jobs in agriculture and moved into urban areas, those that found work enjoyed increased earnings. But at the same time, black unemployment rates increased considerably. In 1950 about 50 percent of both black and white teenagers were employed. Today the employment rate of black teenagers is only about 25 percent.

21. These two hypotheses loosely correspond to individual heterogeneity and state dependence, effects that are empirically difficult to disentangle. See, for example, James J. Heckman and George J. Borjas, "Does Unemployment Cause Future Unemployment? Definitions, Questions and Answers from a Continuous Model of Heterogeneity and State Dependence," Economica, vol. 47 (August 1980), pp. 247-83. 
Thus, looking only at what has happened to earnings exaggerates the amount of progress made. Robert Gordon noted that, whereas in 1964 Levy's estimate of the effect of education on employment was much higher for whites than for blacks, in 1978 it was about the same for the two groups, primarily because the coefficients for whites had fallen. He reasoned that this decline could reflect the growing surplus of collegeeducated young whites.

Alan Blinder questioned the use of transfer receipts as an independent variable in the employability equations. Because employment is a major determinant of transfer receipts, the direction of causality might be the reverse of that implied by Levy's specification. Gordon attributed the increasingly poor employment prospects for young blacks to a vicious circle of crime and entrepreneurial flight. Crime led to the departure of white entrepreneurs to the suburbs, made it impossible for alternative black entrepreneurs to obtain financing or insurance, and thus severely reduced employment opportunities in the cities. William Brainard found this description plausible, but noted that it was not supported by the changes between 1964 and 1978 in either the age or central city coefficients explaining employability. He also observed that, with so much of the variance in employability explained by the previous year's employment experience, which is effectively a lagged dependent variable, the importance of the other explanatory variables is hard to interpret. 